\title{
Osteossarcoma extra-esquelético primário testicular em cão criptorquida
}

\author{
Testicular primary extraskeletal osteosarcoma in the cryptorchid dog \\ Ana Cristina Pacheco de Araújo', Leandro Haczkiewicz Gaiga², \\ Anderson Luiz Seitz ${ }^{3} \&$ David Dreimeier ${ }^{3}$
}

\begin{abstract}
RESUMO
Osteossarcomas extra-esqueléticos primários são raros em pequenos animais, compreendendo menos de $2 \%$ de todos os casos de osteossarcomas em cães. Sabe-se que os principais tumores testiculares em cães são seminomas, tumores das células de Sertoli e de células intersticiais (Leydig), sendo raro o aparecimento de outros tipos de neoplasias. Sabe-se também que cães criptorquidas, unilaterais ou bilaterais, são mais suscetíveis ao desenvolvimento de neoplasias do que cães normais. O objetivo deste estudo é de descrever um caso de osteossarcoma extra-esquelético primário testicular de um canino da raça Fila Brasileiro, de oito anos de idade e criptorquida unilateral, que foi atendido no Hospital de Clínicas Veterinárias da Universidade Federal do Rio Grande do Sul, Porto Alegre, Rio Grande do Sul, Brasil.
\end{abstract}

Descritores: canino, testículo, osteossarcoma.

\section{ABSTRACT}

Primary extraskeletal osteosarcoma is rare in small animals, understanding less than $2 \%$ of all the cases of osteosarcomas in dogs. It is known that the main tumors testiculars in dogs are seminomas, tumors of the cells of Sertoli and interstitial cells (Leydig), being rare the appearance of other types of neoplasmans. One also knows that cryptorchid dogs, unilateral or bilateral, are more susceptible to the development of neoplasmans that normal dogs. The objective of this study is to describe a case of primary extraskeletal osteosarcoma to testicular of a Brazilian dog race Fila, eight years old, unilateral cryptorchid, that was taken care in the Hospital of Clinical Veterinarians of the Federal University of the Rio Grande do Sul, Porto Alegre, Rio Grande do Sul, Brazil.

Key words: canine, testicule, osteosarcoma. 


\section{INTRODUÇÃO}

Osteossarcoma extra-esquelético (OSEE) é uma neoplasia mesenquimal maligna rara de partes moles que não tem conexão com a estrutura esquelética [2,3]. É caracterizada pela produção de osteóide ou osso, algumas vezes acompanhada por cartilagem [8]. A etiologia do OSEE em cães é desconhecida, embora trauma tenha sido relatado na formação de osteossarcoma ocular em gatos [4,11].

Geralmente acomete cães idosos, sem predisposição sexual, sendo as raças Rottweiller e Beagle as mais afetadas [7]. Os locais de maior incidência deste tipo de tumoração no cão, em um estudo de 169 casos foram às glândulas mamárias, sistema digestório, tecido subcutâneo, fígado e baço, havendo ainda relatos em glândulas salivares e tireóide, pulmão, rim, bexiga, olhos e mesentério [7,10]. Metástases são comuns, mas os pulmões estão menos envolvidos que nos osteossarcomas esqueléticos [8]. O prognóstico para o OSEE em cão é pobre, tendo uma previsão média de sobrevida em torno de dois meses [6]. Os principais tumores testiculares em cães são seminomas, tumores das células de Sertori e de células intersticiais [9]. Outras neoplasias encontradas raramente no testículo são mesoteliomas, fibromas, condromas, osteomas, hemangiomas, leiomiomas e os tumores malignos correlatos [5]. O criptorquidismo é o distúrbio mais comum do desenvolvimento sexual no cão, ocorrendo em até $13 \%$; e que tumores ocorrem, freqüentemente, nos testículos que não se encontram no saco escrotal [1]. A proposta deste trabalho é de relatar um caso de osteossarcoma extraesquelético primário testicular de grandes proporções em cão criptorquida, da raça Fila Brasileiro, que foi atendido no HCV da UFRGS, Porto Alegre, RS, Brasil.

\section{DESCRIÇÃO DO CASO}

Cão, macho, da raça Fila Brasileiro, com oito anos de idade e criptorquida, apresentava emagrecimento progressivo e um aumento de volume da região inguinal direita. Ao exame clínico observou-se grande aumento de volume na região inguinal direita (cerca de 30 centímetros de diâmetro) de consistência muito firme e com envolvimento da região peniana. $\mathrm{O}$ saco escrotal apresentava-se edemaciado com presença de um testículo palpável (Figura 1). No exame radiográfico do tórax não foi detectada imagem aparente de metástases, e na radiografia da região abdominal foi observada a presença de uma grande massa extra- abdominal de aspecto ossificado semelhante ao cordão espermático e testículo. Devido a suspeita clínica e radiográfica de neoplasia testicular, o animal foi encaminhado para a cirurgia. O protocolo anestésico utilizado foi anestesia geral inalatória e com o paciente em decúbito dorsal, foi removida a massa tumoral, sendo realizada penectomia total e orquiectomia do testículo esquerdo com ablação do saco escrotal, devido ao envolvimento destas estruturas com o tecido neoplásico. Realizou-se também uma uretrostomia na região escrotal (Figura 2). As estruturas removidas foram enviadas para o exame histológico. Transcorridos dez dias da cirurgia, o animal retornou para avaliação geral e retirada dos pontos, encontrando-se em bom

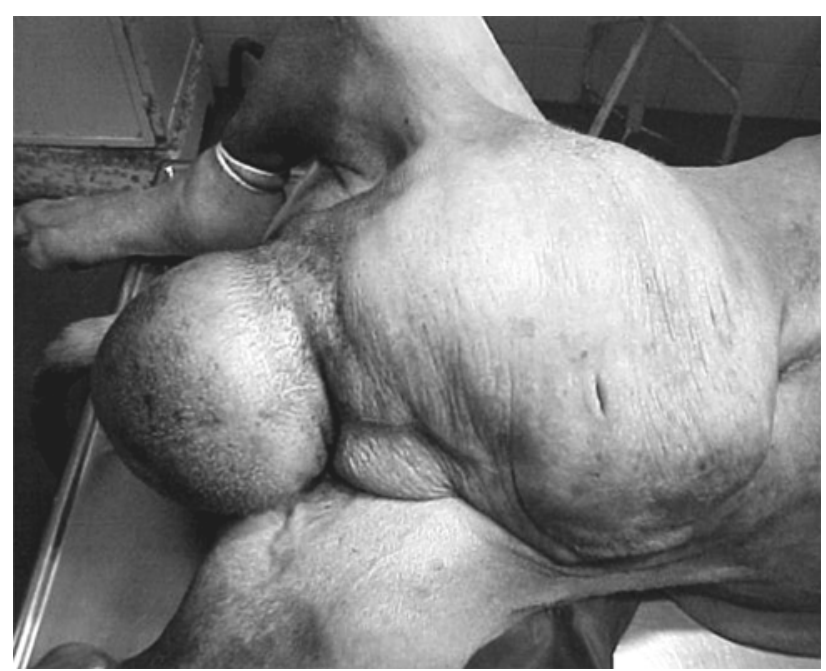

Figura 1. Vista ventral da região inguinal e abdominal do cão, evidenciando a grande massa tumoral, com envolvimento peniano e escrotal.

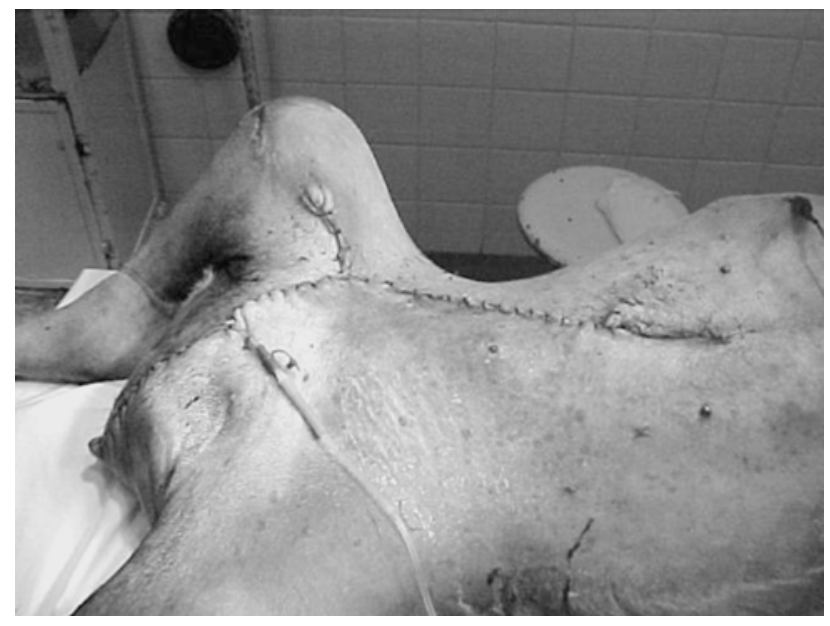

Figura 2. Aspecto final do procedimento cirúrgico, evidenciando a grande sutura da pele e a sonda uretral. 
estado geral, ferida cirúrgica cicatrizada, controle do fluxo urinário normal, ativo e alimentando-se bem (Figura 3). No exame histológico foi diagnosticado massa tumoral com formação de trabéculas ósseas e matriz osteóide, além de áreas de matriz condróide isoladas (Figuras 4 e 5), tendo como diagnóstico final osteossarcoma de testículo ectópico sem envolvimento do osso peniano. Sessenta dias após a cirurgia o animal retornou com anorexia, dificuldade respiratória, emese constante e edema acentuado dos membros pélvicos e região inguinal. Devido à gravidade do caso foi indicada a eutanásia, sendo o corpo enviado para a necropsia. Ao exame macroscópico observou-se a presença de nódulos sólidos e brancos na região pélvica, baço, fígado, bexiga e pulmão, cujo laudo microscópico identificou a presença de intensa proliferação

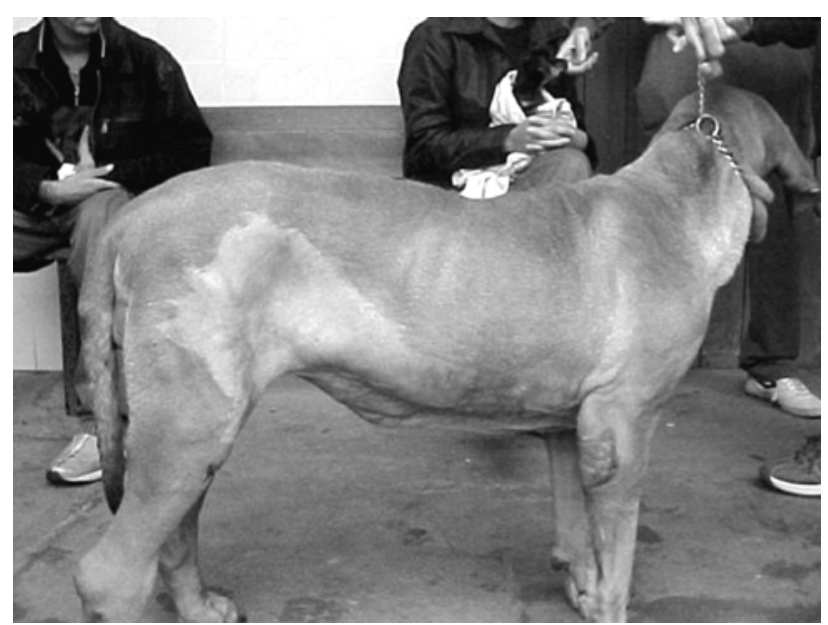

Figura 3. Aspecto do cão após dez dias do pós-operatório, não havendo edema local.

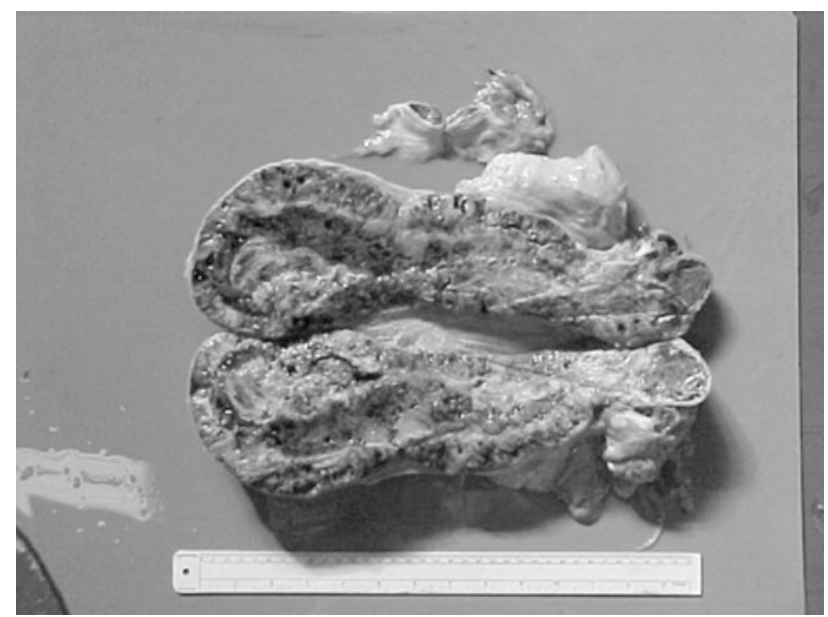

Figura 4. Exame histopatológico, aspecto macroscópico: evidenciando o aspecto ossificado do órgão. de condroblastos fusiformes e células osteoblásticas hipercromáticas, com bordos angulares, e por vezes circundadas por matriz óssea, tendo o diagnóstico final de osteossarcoma nestes órgãos.

\section{DISCUSSÃO}

Este caso representa um exemplo raro de OSEE em medicina veterinária [5], pois foi excluída a presença de osteossarcoma esquelético como origem primária desta neoplasia. Em estudo de 169 casos de OSEE, não se observou a presença desta neoplasia em testículos, sendo a maioria relatada em glândulas mamárias [7]. $\mathrm{O}$ fato de o animal ter apresentado um testículo ectópico, contribuiu para o surgimento da neoplasia, pois tumores testiculares são mais freqüentes em animais criptorquidas [1]. O tempo de sobrevida dos animais com este tipo de neoplasia foram de 60 dias [7], conforme foi visto no caso relatado. E estudos mostraram que animais com OSEE de tamanho excedente a 15 centímetros, de tecido mole ou de glândula mamária, tiveram uma sobrevida de 15 a 105 dias, respectivamente [2,7]. Em 14 cães com OSEE, dez foram eutanásiados e apresentaram metástases (média de aparecimento de 59 dias) no fígado (cinco casos) e no pulmão (três casos), sendo que em dois casos não foram localizadas neoplasias em outros órgãos [6]. O prognóstico do OSEE é pior por ser uma variação mais maligna de osteossarcoma, pelos pacientes apresentarem os sintomas mais tardiamente e pelo curso da

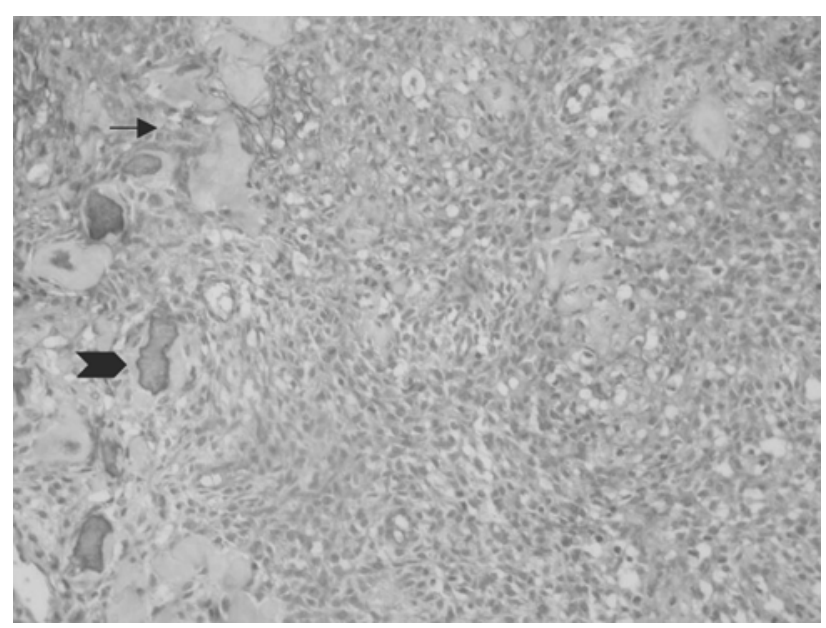

Figura 5. Exame histopatológico, aspecto microscópico: observa-se a presença de ilhas de matriz osteóide mineralizada $(\rightarrow)$ e ocasionais proliferações de tecido condróide $(\boldsymbol{D})$ circundadas por células fusiformes com citoplasma eosinofílico, com hipercromasia e pleomorfismo nuclear evidentes. Bar: $5 \mathrm{~mm}$. 
doença ser mais lento [7]. Apesar da intervenção cirúrgica ter tido êxito, sem dúvida que o tamanho exagerado do OSEE testicular deste caso, contribuiu para que a sobrevida do animal tenha sido breve, mas que, conforme a literatura consultada, não poderia ter sido diferente devido a malignidade severa deste tipo de neoplasia. É sabido também que a procura precoce por tratamento aumenta a expectativa de sobrevida do paciente com este tipo de tumoração, além da associação da cirurgia com a quimioterapia.

\section{REFERÊNCIAS}

1 Aclaud H.M. 1998. Sistema reprodutor do macho. In: Carlton, W. W., Macgavin, M. D. (Eds). Patologia Veterinária Especial. 2.ed. São Paulo: Artmed, p. 575- 590.

2 Bane B.L., Evans H.L. \& Ro J.Y. 1990. Extraskeletal osteosarcoma. A clinicopathology review of 26 cases. In: Cancer (New York, EUA). 66: 62-70.

3 Eu K. W., Mohan C., Tan S. K. \& Lim-Tan S. K. 1991. Extrasketal osteogenic sarcoma. In: Ann Acad. Med. (Singapura). 20: 798-800.

4 Heldmann E., Anderson M.A. \& Wagner-Mann C. 2000. Feline osteosarcoma: 145 cases (1990-1995). In: Journal of the American Animal Hospital Association. (New York, U.S.A) 36: 18-21.

5 Jones T.C., Hunt R.D. \& King N.W. 2000. Genital System. In: Jones, T. C., Hunt, R. D., King, N. W. (Eds). Veterinary Pathology. 6 ed.U.S.A.: pp1214- 2000.

6 Kuntz C.A., Dernell W.S., Powers B.E. \& Withrow S. 1998. Extraskeletal Osteosarcomas in dogs: 14 cases. In: Journal of the American Animal Hospital Association. (New York, U.S.A) 34: 26-30.

7 Langenbach A., Anderson M.A., Dambach D.M., Sorenmo K.U. \& Shofer F.D. 1998. Extraskeletal osteosarcomas in dogs: a retrospective study of 169 cases (1986-1996). In: Journal of the American Animal Hospital Association. (New York, USA) 34: 113-120.

8 Lima M.A., Rivas L.G., Grecco M.A.S. \& Drumond J.M.N. 1998. Osteossarcoma extra-esquelético primário da região frontal. In: Revista da Associação Médica do Brasil. (Curitiba, Brasil) 44: 43-46.

9 Loar A.S. 1992. Tumores do sistema genital e glândulas mamárias. In: Ettinger, S. J. (Ed) Tratado de medicina interna veterinária. 3 ed. São Paulo: Manole, pp 1894-1906.

10 Stimson E.L. 2000. Extraskeletal osteosarcoma in the duodenum of a cat. In: Journal of the American Animal Hospital Association. (New York, U.S.A) 36: 332-336.

11 Waters D.J. \& Dawn M.C. 1998. Skeletal Neoplasms. In: Morrison, W. B. (Ed) Cancer in Dogs and Cats. 3 ed. São Paulo: Manole, pp 645-668. 